\title{
The 'New Normal' in Higher Education: Innovative teaching and learning technologies and practices during a crisis
}

\author{
Nicholas Blessing Mavengere', Shepard Pondiwa², Tinashe Charles \\ Matiyenga ${ }^{3}$, Francis Manzira ${ }^{4}$ and Alfred Mutanga ${ }^{5}$ \\ Bournemouth University, United Kingdom? . Midlands State University, Zimbabwe ${ }^{2}$ \\ National University of Science and Technology, Zimbabwe ${ }^{3}$. University of Venda, South \\ Africa ${ }^{4}$. University of Limpopo ${ }^{5}$ \\ Email: \{nmavengere@bournemouth.ac.uk><pondiwas@msu.ac.zw><tinashe.matiyenga@ \\ nust.ac.zW><Francis.Manzira@univen.ac.za><alfred.mutanga@ul.ac.za\}
}

\section{ABSTRACT}

\section{Purpose}

The purpose of this paper is to analyze the effectiveness of innovative technologies and practices adopted to enhance teaching and learning in higher education settings during a crisis e.g. the COVID-19 pandemic in developing countries. We seek to highlight the need for digital and technological transformation in the teaching and learning practices in response to crisis for adaptation to the 'new normal'.

\section{Design /Methodology approach}

Using a qualitative research approach, data was collected through an online questionnaire and online interviews with lecturers who conducted teaching during the COVID-19 pandemic in developing countries. The countries from where data was collected are Egypt, Zimbabwe, South Africa, Tanzania, Namibia and Botswana. The aim was to highlight transformational processes required for to remote learning during the COVID-19 pandemic. In doing so, we note the adaptable approaches that are useful in times of crisis to promote learning.

\section{FINDINGS, CONTRIBUTIONS AND IMPLICATIONS}

The results highlight measures adopted to promote remote learning during a crisis, such as, COVID-19. The contributions include a conceptual model for innovative technologies and practices to the rapid shift to remote learning and ensuring qualities of learning. In developing countries' context, making use of existing infrastructure, system and organizations is necessary to promote learning in higher education.

\section{INTRODUCTION}

There have been changes in the way teaching and learning is conducted in tertiary institutions throughout the world in recent years and challenges have been observed (Martinez, 2020; Rapanta et al, 2020; UNESCO, 2020] [1,2,3]. Most of these transformations have been in response to a crisis. Some institutions have transformed their programmes in response to natural disasters while others' transformation has been in response specifically to the COVID-19 pandemic (Dhawan, 2020; Mishra et al, 2020, $\mathrm{Wu}, 2020][4,5,6]$. The purpose of this paper is to analyze innovative technologies and practices that have been adopted to enhance teaching and learning in higher education settings during a crisis e.g. the COVID-19 pandemic 
in developing countries. The paper also discusses the impact of the 'new normal' on active learning, collaborative learning, constructive learning, contextual learning, reflective learning and transfer learning. In addition, the paper highlights the need for technological transformation in the teaching and learning practices in response to crisis for adaptation to the 'new normal'. The "new normal" in this research refers to the state to which higher education institutes settle following a crisis when this differs from the situation that prevailed prior to the start of the crisis, in this case COVID-19 pandemic.

There is literature, already in the higher education domain, that shows that there have been some efforts to transform teaching and learning in times of a crisis, for instance, ["Author" 2021; Motala and Menon, 2020; UNESCO, 2020] [3,7,8]. The outbreak of COVID-19 occasioned the massive adoption of virtual learning platforms in many institutions of higher learning. It has become inevitable, in the current COVID-19 era, for educators to integrate ICT in their teaching and rapidly replace traditional teaching methods with modern ones which are ICT based. The provision of education using ICT and mobile communication platforms has become a common practice at most institutions particularly in developing countries. We are motivated to investigate this ICT adoption and application in times of crisis by higher education as summed up by the research question: how can innovative technologies and practices be applied in times of crisis, such as a pandemic in developing countries to ensure qualities of learning?

\section{THEORETICAL BACKGROUND}

\subsection{QUALITIES OF LEARNING}

We should seek to achieve qualities of learning in higher education (Baran 2011; Wang and Torrisi-Steele 2015; "Author" 2018, Wu 2020] [6,9,10,11]. Technology could be adopted in efforts to foster qualities of learning. Interest in active learning is increasing, many instructors are trying out new procedures and report them to their fellow instructors (Hartikainen et al., 2019; Motala and Menon, 2020; UNESCO, 2020; $W u, 2020][3,6,8,12]$. In this research we investigate the use of technology to enable learning and also maintain or further improve the quality of learning during critical times. Ruokamo and Pohjolainen [1998, p. 293] [13] suggest the following qualities of learning;

1. Active - Learning process is active, and learners are engaged in mindful processing and they are responsible for the result.

2. Constructive - Knowledge is constructed from previous knowledge by learners.

3. Collaborative - Learners work in co-operation with each other and exploiting each other's skills in building new knowledge

4. Intentional - A cognitive objective is set and learners try actively and willingly to achieve it.

5. Contextual - Learning is based on problem-based real life examples or they are introduced through case-based i.e. meaningful real-world tasks.

6. Transfer - Learners' ability to transfer learning from different situations and contexts.

7. Reflective - Learners' ability to sum up what they have learned including the process and outcomes.

\subsection{COMMUNITY OF INQUURY}

Learning conducted through the online environment and platforms should still attain qualities of learning. To attain this, the community of inquiry model defines 
a good virtual learning environment [Garrison and Arbaugh, 2007] [14]. This is done through three major components namely cognitive presence, social presence and teaching presence as illustrated in Figure 1. Lowenthal and Lowenthal $[2010, \mathrm{p}]$ [15] considered "social presence as a theory that explains the ability of people to present themselves as 'real people' through a communication medium. Most studies on social presence focus on how students present themselves and/or are perceived as 'real' people online". Garrison et al. [2000] [16] suggest emotional expression, open communication and group cohesion as social presence indicators. Cognitive presence is the ability to construct and confirm meaning through sustained reflection (Anderson, Rourke, Garrison, \& Archer, 2001). Fiock $[2020][17,18]$ emphasizes the value of learners' reflection to increase cognitive presence. Teaching presence is the design, facilitation and direction of cognitive and social presence to support learning [Garrison and Arbaugh, 2007; Garrison et al., 2000] $[14,16]$.

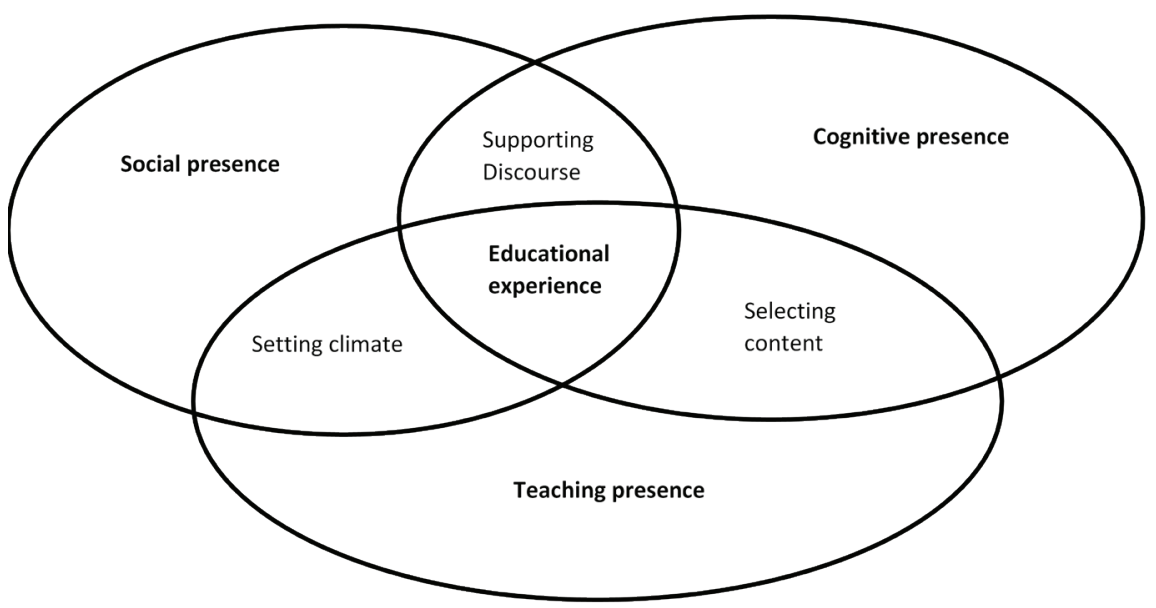

Figure 1: Community of inquiry framework [Garrison and Arbaugh 2007] ${ }^{[14]}$

\section{METHODOLOGY}

Denzin and Lincoln (2005) [19] note that the qualitative research approach is useful for providing insights into problems and helps develop ideas. This is our research agenda; we utilize the qualitative research approach, (please see Appendix A: Questionnaire]. This is done by collecting data through an online questionnaire from higher education teaching staff, that includes, lecturers, laboratory technicians, heads of academics and professors as shown in Figure 2 below. Of the 17 respondents, about $70 \%$ are male and $30 \%$ females. These are teaching staff who conducted teaching during the COVID-19 pandemic in developing countries namely Egypt, Zimbabwe, South Africa, Tanzania, Namibia and Botswana.

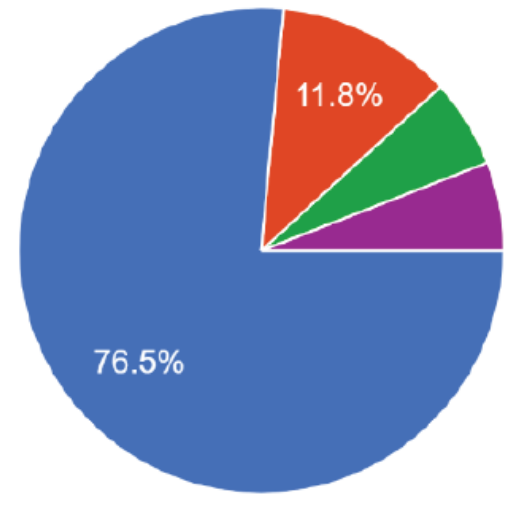

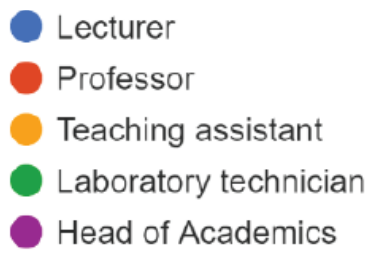

http://apc.aast.edu 
Figure 2: Proportion of respondents

The education levels of respondents are 52,9\% PhD, 35,3\% Masters, 5,9\% bachelor and $5,9 \%$ Diploma. This shows that the respondents are well educated and fit for our research interests of understanding innovative technologies and practices in times of crisis. In addition, $82,4 \%$ of the respondents have more than five years higher education teaching experience.

\section{RESULTS}

In highlighting the results, first we highlight efforts to promote qualities of learning in the remote learning context. Secondly, we highlight the theoretical contribution and finally explain the practical implications.

\subsection{QUALITIES OF LEARNING IN THE REMOTE LEARNING CONTEXT}

4.1.1 Active Learning

Active learning refers to a broad range of teaching strategies which engage students as active participants in their learning during class time with their instructors. Active learning is generally defined as any instructional method that engages students in the learning process. In short, active learning requires students to engage in meaningful learning activities and reflect on these activities. Active learning provides an opportunity for all students in a class to think, engage, apply and synthesize the learning material and come up with solutions using the taught material. It is based on a concept that puts the student at the center of the learning process. The student learns tasks through actively participating. Prior to the outbreak of COVID-19, instructors would organize active learning tasks in class and they would monitor the learners in the execution of these tasks. The 'new normal' has ushered in some drastic changes to this as these tasks are now done outside of the traditional classroom. Lecturers who were interviewed indicated that the 'new normal' and the use of ICT in education promoted active learning. For example, please see respondent quote below:

"Online e-learning approach was used which involved using various electronic devices [e.g. computers, laptops, smartphones, etc.] with internet availability in synchronous or asynchronous environmental conditions. This approach of e-learning provides a platform that makes the process of education more student-centered, creative, and flexible".

\subsubsection{Constructive LEARNing}

Mulyati et al. [2021, p. 6400] [20] note that "constructivism is the process of building or compiling new knowledge in students' cognitive structures based on experience". In remote learning, this would be promoted by cognitive presence. But there are challenges in remote learning, for instance, amongst the challenges cited was that at times it is difficult to know whether the task was done by the student or not since this is done at home. Activities, such as class discussion, small group discussion, debate, posing questions to the class, think-pair-share activities, short written exercises and polling the class [Bonwell and Eison, 1991] [21] promote constructive learning. It is important to note that the lack of and limited access to learning technologies experienced during a crisis particularly in the developing world is a barrier to constructive learning. About $70 \%$ of respondents suggested that students had good access to learning technologies.

\subsubsection{Collaborative LeARNING}

Collaborative learning involves learners or trainees working in pairs or small groups to discuss concepts or to work out solutions to given problems or tasks. The adoption of the virtual classroom in most developing countries has come with 
some challenges to the concept of collaborative learning. While it is relatively easy to collaboratively learn in developed countries due to developments in internet infrastructure, in developing countries this concept has faced some challenges to those who have attempted to implement it. In response to COVID-19, institutions of higher learning have come up with strategies meant to enable learning to take place even during the lockdowns. Most institutions prior to COVID-19, conducted lectures physically. This made collaborative learning easy to organize as students were put in groups where they would physically meet and solve issues. In most developing countries where the rate of access to internet infrastructure- and connectivity outside the university campus is very low, collaborative learning online has not been easy. Results from this research indicated that $70 \%$ of lecturers indicated that group work assignments were not submitted on time on the online platform as compared to the physical platform.

\subsubsection{INTENTIONAL LEARNING}

Intentional learning recognizes the efforts of students to actively and willingly achieve cognitive objectives. There were differing levels of support offered by higher education institutions during the COVID-19 pandemic. The respondents noted such measures as training, internet access, mobile gadgets and data bundles. This support creates an appropriate environment for intentional learning. However, a respondent noted the need for "a holistic approach which takes both students and lecturers' needs" for remote learning to achieve intentional learning.

\subsubsection{CONTEXTUAL LEARNING}

Contextual learning includes tasks derived from the real world and could involve techniques as case-based or problem-based real-life examples. Learning during a crisis provides unique context that could be taken advantage of in informing the learning process and outcomes. For example, remote learning brought up technology limitations that students could take up as cases and problems meant to be solved as part of the learning. However, a respondent noted that remote learning "was not an easy transition due to resource limitations" but there were efforts "to allow people to adjust to the new normal".

\subsubsection{TRANSFER LEARNING}

"Learners are able to transfer learning from the situations and contexts, where learning has taken place and use their knowledge in other situations" ["Author", 2018] [11]. Transfer learning is demonstrated by students during assessment. Assessment during remote learning was a challenge and called for revisions of assessment tasks and techniques to suit the online assessment environment.

\subsubsection{Reflective LEARNING}

Schön [1983] [22] describes reflective practice as a dialogue between thinking and doing through which the learner becomes more skilled. Institutions of higher learning aim to produce learners who are skilled. In Zimbabwe, for example, the Ministry of Higher and Tertiary Education has adopted a 5.Ө education thrust which among other things focuses on innovation, industrialization and research. This places reflective education at the center of such learning. This means that as institutions reacted and continue to react to COVID-19, the ultimate aim is to produce graduates who are skilled. Thus, the adoption of the virtual learning platform and other strategies should support this vision.

\subsection{THEORETICAL CONTRIBUTIONS}

Innovative technologies and practices to the rapid shift to remote learning and 
ensuring qualities of learning are illustrated in Figure 3 . We noted that innovative remote learning technologies, such as, learning management systems like Moodle and communication platforms like WhatsApp were used in innovative practices that are student-centered, creative and flexible to create an appropriate leaning environment as defined by the community of inquiry model to promote qualities of learning. There is need to adjust the teaching process to remote learning using for instance community of inquiry principles [Garrison and Anderson, 2003] [23]. This calls for inclusion of social presence, teaching presence and cognitive presence. There are various technological requirements and skills for remote learning, for instance learning management system support and digital pedagogy. These are essential for successful remote learning. In addition, there is increased workload in remote learning.

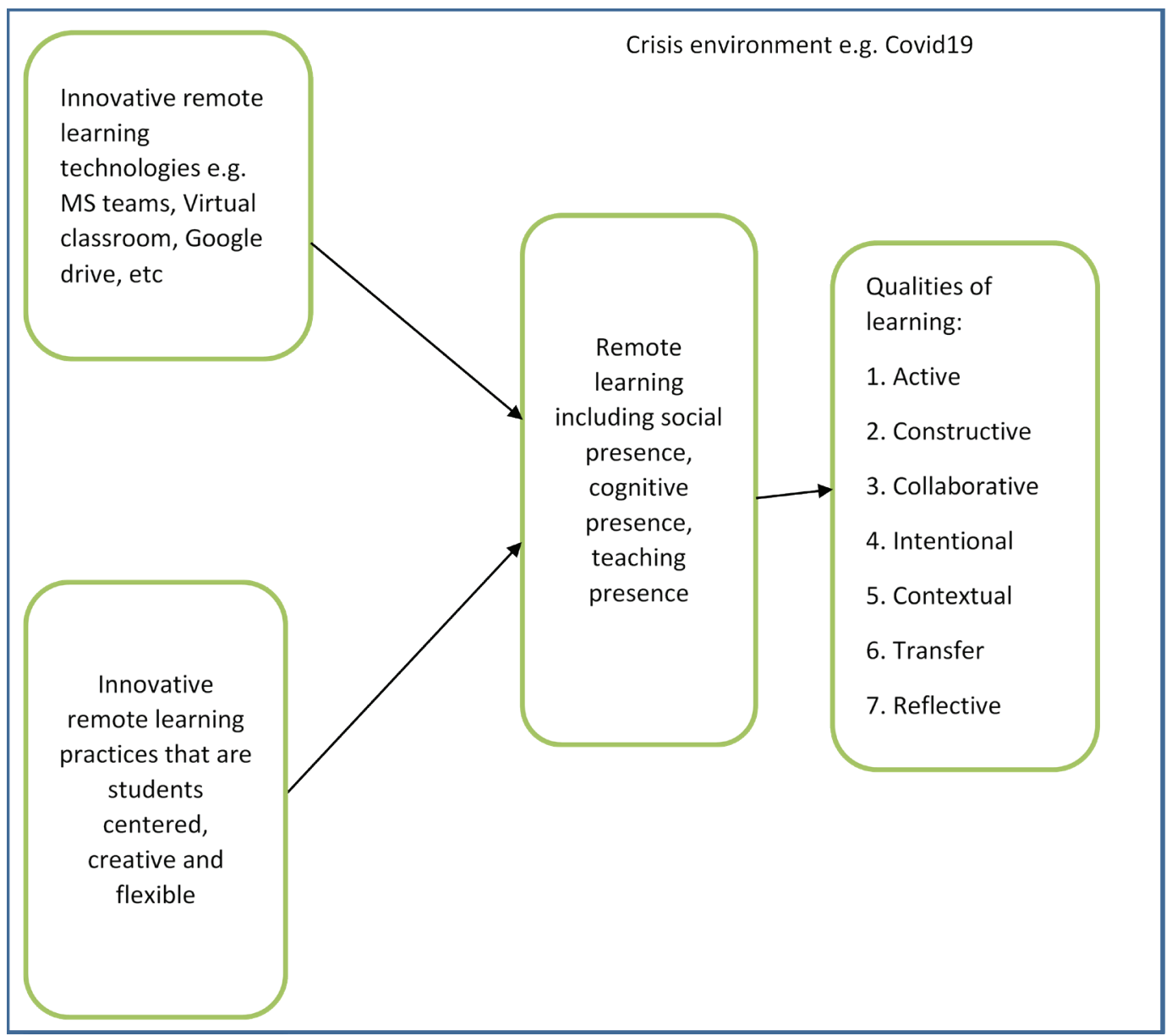

Figure 3: Innovative technologies and practices to the rapid shift to remote learning and ensuring qualities of learning

The perceived levels of qualities of learning during the remote learning during a crisis, specifically COVID-19 by the respondents is illustrated in Figure 4.

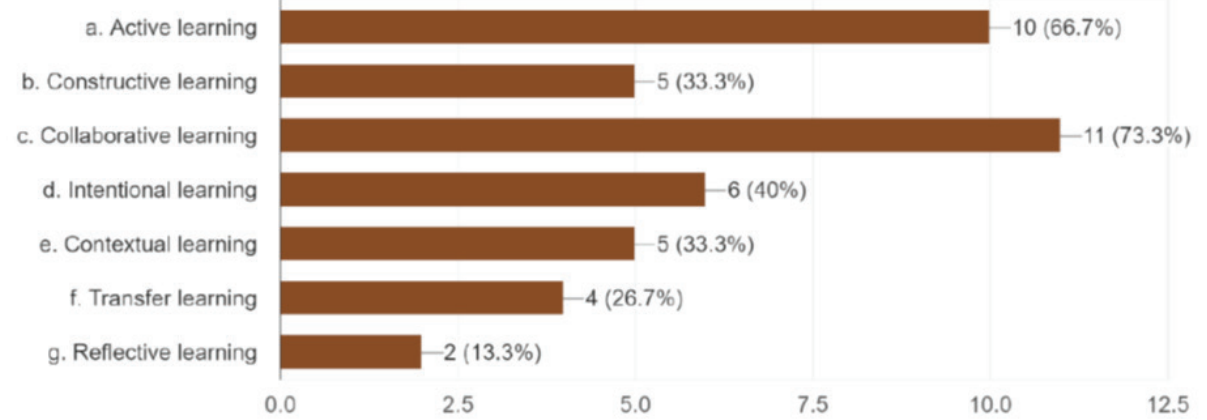

Figure 4: Perceived qualities of learning in the "new normal" 


\subsection{Practical implications}

This study shows that during times of crisis, innovative technologies and practices are essential to promote learning. In developing countries' context, making use of existing infrastructure, systems and organizations is necessary to promote learning in higher education. COVID-19 has provided opportunities for institutions and individuals to embrace technology and improve service delivery. Even in those institutions that were pessimistic about embracing the use of ICT, the COVID-19 induced lockdowns have changed the way ICT is perceived and utilized.

\section{DISCUSSION}

\section{Perception of the 'NeW nORMAL'}

A new normal can be described as a state to which a society settles following a crisis, when this differs from the situation that prevailed prior to the start of the crisis. In this case the 'new normal' is a situation in which teaching and learning is not restricted to the brick-and-mortar classroom. In the 'new normal', learning is largely virtual and ICT based. This 'new normal' also means that the time in which teaching and learning happens is flexible as compared to the pre-COVID-19 period in which there were fixed times in which learning was done. This research observed that most of the lecturers interviewed appreciated the new normal that has been ushered in by the outbreak of COVID-19.

\section{TECHNOLOGICAL CHANGES USED IN THE 'NEW NORMAL'}

The proliferation of mobile devices in institutions of higher learning has radically shaped andragogical and pedagogical aspects of learning. A lot of technological innovations have been introduced in education. Mobile phones, laptops, tablets, radios and T.Vs have been adopted and used in universities and other institutions of learning in most developing countries. Mobile learning (m-learning) has been increasingly incorporated into formal classroom delivery in various universities [Schuck, Kearney, \& Burden, 2017] [24].

While mobile phones are known to be very popular among university students for increasing their social inclusion and connectedness as well as providing a sense of security as they can contact others in times of distress or emergency [Balakrishnan \& Raj, 2012] [25], the outbreak of COVID-19 has resulted in the use of the mobile phones as one of the major teaching and learning devices. COVID-19 has promoted the increased adoption of online learning in universities and most private schools in developing countries. Universities have encouraged their students to bring their own learning devices to class.

The Midlands State University in Zimbabwe has adopted a Buy Your Own Device [BYOD] policy to facilitate m-learning (Pondiwa and Phiri, 2019] [26]. While students have always been bringing their own ICT gadgets to university before the outbreak of COVID-19, the outbreak of COVID-19 and the subsequent lockdowns that followed increased the need to for students to have their own devices.

Universities responded to the COVID-19 outbreak in several ways. The better resourced ones were quick to adjust by closing and quickly coming up with alternatives of virtual teaching and learning. Some gave their students pre-recorded learning materials while others offered online learning with learners getting lecture material in real time. Other universities provided their lecturers with teaching materials such as internet data bundles and devices for lecture deliveries. 


\section{CONCLUSION}

This research shows innovative technologies and practices to promote learning in higher education during a crisis e.g. COVID-19 pandemic. Existing technology infrastructure e.g. mobile phone and applications such as WhatsApp were used for learning purposes in higher education. Institutions have adapted and continue transforming their way of doing business. There has been an increase in the number of organizations that offer online services. Educators and learners have also transformed educational systems in order to cope with requirements of learning during a crisis, such as COVID19 pandemic.

\section{REFERENCES}

[1] Jacob Martinez, "Take this pandemic moment to improve Education", Internet:https://edsource.org/2020/take-this-pandemic-moment-to-improve, June, 2020.

[2] Rapanta, C., Botturi, L., Goodyear, P. et al., "Online University Teaching During and After the Covid-19 Crisis: Refocusing Teacher Presence and Learning Activity." Postdigital Science and Education, vol. 2, pp.923-945, July 2020.

[3] UNESCO, "COVID-19 educational disruption and response." Internet: https:// en.unesco.org/themes/education-emergencies/ coronavirus-school-closures, March, 2020

[4] Shivangi Dhawan, "Online Learning: A Panacea in the Time of COVID-19 Crisis", Journal of Educational Technology Systems 2020, Vol. 49[1] 5-22.

[5] Mishra, L., Gupta, T., \& Shree, A.," Online teaching-learning in higher education during lockdown period of COVID-19 pandemic." International Journal of Educational Research Open, Vol.1, 100012, 2020.

[6] $\mathrm{Wu}, \mathrm{Z}$, "How a top Chinese university is responding to coronavirus. World Economic." Internet: https://www.weforum.org/agenda/2028/03/coronaviruschina-the-challenges-of-onlinelearning-for-universities/, . 16,March,2020, [accessed 13 July 2020]

[7] Shireen Motala,Kirti Menon, "In search of the 'new normal': Reflections on teaching and learning during Covid-19 in a South African university." Southern African Review of Education with Education with Production, Vol. 26, No. 1, pp.185 - 195, July 2020

[8] Baran, Evrim," The transformation of online teaching practice: Tracing successful online teaching in higher education.", Doctoral thesis, lowa State University, United States, 2011.

[9] Victor C. X. Wang1Geraldine Torrisi-Steele, "Online Teaching, Change, and Critical Theory. New Horizons in Adult Education \& Human Resource Development, Wiley Periodicals, Inc., Vol. 27, Issue3, pp. 18-26, 2015

[10] Victor C.X. Wang1Geraldine Torrisi-Steele, "Online Teaching, Change, and Critical Theory. New Horizons in Adult Education \& Human Resource Development, Wiley Periodicals, Inc., Vol. 27, Issue3, pp. 18-26, 2015

[11] Mavengere, N., Ruohonen, M.,"Context and user needs in virtual learning in pursuit of qualities of learning," Education and Information Technologies, Vol.3, Issue 4, pp.1607-1620, July 2018

[12] Hartikainen S, Rintala $H$, Pylväs L, Nokelainen P. "The Concept of Active Learning and the Measurement of Learning Outcomes: A Review of Research in Engineering Higher Education." Education Sciences, Vol. 9, issue 4, pp. 279, 2019. https:// doi.org/10.3390/educsci9040276

[13] Ruokamo, H., \& Pohjolainen, S.," Pedagogical Principles for Evaluation of Hypermedia-Based Learning Environments in Mathematics." JUCS-Journal of 
Universal Computer Science, Vol.4, Issue 3, pp. 292-307, 1998.

[14] Garrison, D. R., \& Arbaugh, J. B.," Researching the community of inquiry framework: Review, issues, and future directions." The Internet and Higher Education, Vol.10, Issue 3,pp. 157-172, 2007.

[15] Lowenthal, D. A., \& Lowenthal, P. R.," A mixed methods examination of instructor social presence in accelerated online courses." Paper presented at the annual meeting of the American Educational Research Association, Denver, C0.2010. doi: 10.4018/978-1-4666-9582-5.ch006.

[16] Garrison, D. R., Anderson, T., \& Archer, W.," Critical inquiry in a text based environment: Computer conferencing in higher education." The Internet and Higher Education, Vol. 2, pp. 87-105, 2020.

[17] Anderson, T., Rourke, L., Garrison, D. R., \& Archer, W. "Assessing teaching presence in a computer conference context." Journal of Asynchronous Learning Networks,Vol. 5, Issue 2, 2001.

[18] Fiock H.S. "Designing a Community of Inquiry in Online Courses," International Review of Research in Open and Distributed Learning, Volume 21, pp 134-152, 2020.

[19] Denzin, N.K. and Lincoln, "Introduction: The Discipline and Practice of Qualitative Research." Handbook of Qualitative Research, 3rd Edition, Sage, Thousand Oaks, pp.1-32, 2005.

[20] T.S. Mulyati and E. Yetti, Analysis Of Constructive Learning Models In Forming Religious Characters of Early Childhood. Psychology and Education Journal, 58[2], pp.6399-6403, 2021.

[21] Bonwell, C.C. and Eison, J.A., " Active Learning: Creating Excitement in the Classroom", ASHE-ERIC Higher Education Reports. ERIC Clearinghouse on Higher Education, The George Washington University, One Dupont Circle, Suite 630, Washington, DC 20036-1183, 1991.

[22] Donald A. Schon and Vincent DeSanctis, The Reflective Practitioner: How Professionals Think in Action." The Journal of Continuing Higher Education, 34[3], pp. 29-30, 1983.

[23] D.R. Garrison, T. Anderson, and W. Archer, A theory of critical inquiry in online distance education. Handbook of distance education, $7[4]$, pp.113-127, 2003.

[24] S. Schuck, M. Kearney, K. and Burden, Exploring mobile learning in the third space. Technology, Pedagogy and Education, 26[2], pp.121-137, 2017.

[25] V. Balakrishnan and R. G. Raj, Exploring the relationship between urbanized Malaysian youth and their mobile phones: A quantitative approach. Telematics and Informatics, 29[3], pp.263-272, 2012.

[26] S. Pondiwa, and M. Phiri, M., Challenges and Opportunities of Managing Social Media Generated Records in Institutions of Learning: A Case of the Midlands State University, Zimbabwe. In International Conference on Sustainable ICT, Education, and Learning (pp. 145-156). Springer, Cham, 2019.

\section{APPENDIX A - QUESTIONNAIRE / INTERVIEW QUESTIONS}

Demographic questions

1. What is the name of your university/college?

2. What is the name of your department?

3. How long have you worked here?

4. What is your current role/position in the organisation?

5. In which country is your university / college geographically located?

6. What is your gender? - Male or Female

7. What is your level of education? - Certificate, Bachelor, Masters, PhD 
Research questions

1. What are the practices used for learning in higher education during the COVID19 pandemic in developing countries?

2. What are the technologies [this could include mobile based, TV, radio, etc.] used for learning in higher education during the COVID19 pandemic in developing countries?

3. How accessible were these technologies?

4. How was the transition done to continue learning in higher education during the COVID19 pandemic in developing countries?

a. Why was the transition done this way?

5. What were the facilitating conditions offered by the university?

6. What are the lessons i.e. adaptable approaches that could be used to transition to remote learning during a crisis?

7. What is your perceived "New Normal" in Higher Education based on the Innovative teaching and learning technologies and practices experience during COVID19

8. How does the "new normal" promote
a. Active learning
b. Constructive learning
c. Collaborative learning
d. Intentional learning
e. Contextual learning
f. Transfer learning
g. Reflective learning 